\title{
Color Harmony Integration-driven Design Process for Aesthetic Village
}

\author{
Hyunsoo Lee ${ }^{1}$, Daseul Kim² ${ }^{2}$ Jihyoun Hwang ${ }^{3}$ \\ 1,2,3 Yonsei University \\ 1'hyunsl@yonsei.ac.kr²ektmf5646@naver.com3jihyounh@gmail.com
}

This paper describes the color design process of the house in the village. The color design process proposed in this paper constitutes design stages such as color selection, color application, and color design analysis and evaluation. In the color selection step, a method of arranging colors using a color pallet or a color scheme is described. The color application stage includes the process of creating a village color design alternatives by specifying the color information of the hue, value, and saturation based on the BIM model. The color analysis stage is to numerically identify the color design attributes of the generated color design alternatives. The reason for color analysis and evaluation is to produce various design alternatives with the color harmony and improve the quality of the design.

Keywords: Color Palette, Environmental Color, Color Harmony, Color Scheme, Color Design Analysis

\section{- INTRODUCTION}

It is important to design a beautiful village to improve the quality of life. However, most of the villages built in modern times are not very beautiful, nor are they characteristic designs, nor do they reflect regional characteristics. If we solve this problem and create a more beautiful village than now, can we make people happier? So how do you make a beautiful village? There are many ways we can think of how to make a beautiful village. One of the ways to create a beautiful village efficiently is to utilize colors(Boeri 2017, Gou and Wang 2008, Lancaster 1996). Until now, color is a design element that the architect did not show much interest in comparison with other architectural elements in order to improve the quality of the design. Why, then, did architects have less interest in color?
This is because the form is considered more important than the color in order to meet the required function. Another reason is that architects have received relatively more education in terms of form, but perhaps less educated about color. Or it may be because color was accepted as not a design area of architecture. However, considering the times when emotion is important, color is just as important as form. Generally, colors are considered emotional and forms are considered rational. In this regard, this paper is motivated to deal with the process of color design, which architects have not dealt with design process heavily. And to provide aesthetic and well-being experiences for people by improving the aesthetic characteristics of the village. This study aims to improve the aesthetic characteristics of villages by developing a color harmony integration-oriented color design process that architects can easily apply in col- 
lective housing deign.

In general, in traditional color design, it is true that color design has been carried out by designer intuition rather than other designs. This is because color has the property of design that is highly subjective and connected with emotion. The color harmony problem, which has also relied on the intuition of the designer, is one of the most important issues related to color design. In traditional color design, the quality of the design has been affected by the ability of the intuition and subjectivity of the designer. Another problem with traditional color design is that some design alternatives are created and then the final design is decided. However, this problem can be solved by using digital color. In other words, it is possible to systematically design color by the design process based on digital color. Previous research on color design process has been insufficient. In particular, there have been few studies on architectural color design process using digital technology.

The quality of color design can be improved by utilizing the color design process. It will not only provide people with the pleasure of aesthetic experience, but also enhance the identity of architecture. In this sense, this study deals with the problem of color design process. This study attempts to deal with the color design process in terms of the color design of a village with aesthetic experience. The color design process described in this paper focuses on the integration of colors. The integration of colors has much to do with the harmonization of colors such as the unity of colors.

\section{- Color Design Process Aiming Color Unity Towards Harmony of Consistency}

Color is one the most important yet difficult factors in visual design. One challenge is generating harmonious color schemes(Hu et all 2012). Color in the man-made environment influences spatial perception by affecting the character of the space, the clarity or distortion of the spatial envelope, its proportioning, and its articulation(Tosca 2002). Color is an element of architecture, thus color design have to be integral part of architectural design process. From this point of view, the color design process determines the direction of color design and greatly affects the quality of color design. Despite this importance, however, it is difficult to find a color design process that architects can easily use. This paper, which was started with the focus on this problem, has the motivation to develop a color design process that architects can easily and systematically use. The color design process(Ju and Lee 2018, Smith 2003)) to be discussed in this paper consists of three stages shown in Figure 1.

\section{Step 1. COLOR SELECTION}

The first step is the selection of the color scheme to choose the appropriate color in the stored color scheme database. The choice of color scheme is found by the search term of emotional words from regional images. In this paper, color palette $\mathrm{FX}$ is used to create color scheme through regional images of villages are located [1]. The FX analyzes color images and provides harmonious color scheme with colors with the form of Hex, RGB, and HSL. After that, color palette can be created according to color schemes. The color scheme is generated considering the harmony theory of color(Birren 1969, Hard and Sivik 2001, Hu et al 2014, Kopacz 2003, Linton 1999, Pile 1997). In this paper, the color system used to generate the color scheme is the NCS color model. NCS, Natural Colour System is a logical colour system which builds on how the human being sees colour. The system starts from six elementary colours, which are perceived by human beings as being "pure". The four chromatic elementary colours are yellow $(\mathrm{Y})$, red $(\mathrm{R})$, blue $(\mathrm{B})$ and green $(\mathrm{G})$, and the two non-chromatic elementary colours are white (W), black (S). All other colours can be described in terms of their degree of resemblance to the elementary colours[2].

The NCS Colour Triangle(Figure 2) is a vertical section through the colour space. Here you find different nuances of the actual blue hue R90B. The base of the triangle is the grey scale from white $(\mathrm{W})$ to black $(S)$ and the apex of the triangle is the maximum 
Figure 1

Color Harmony

Integration-

oriented Design

Process

Figure 2

THE NCS Color

Triangle

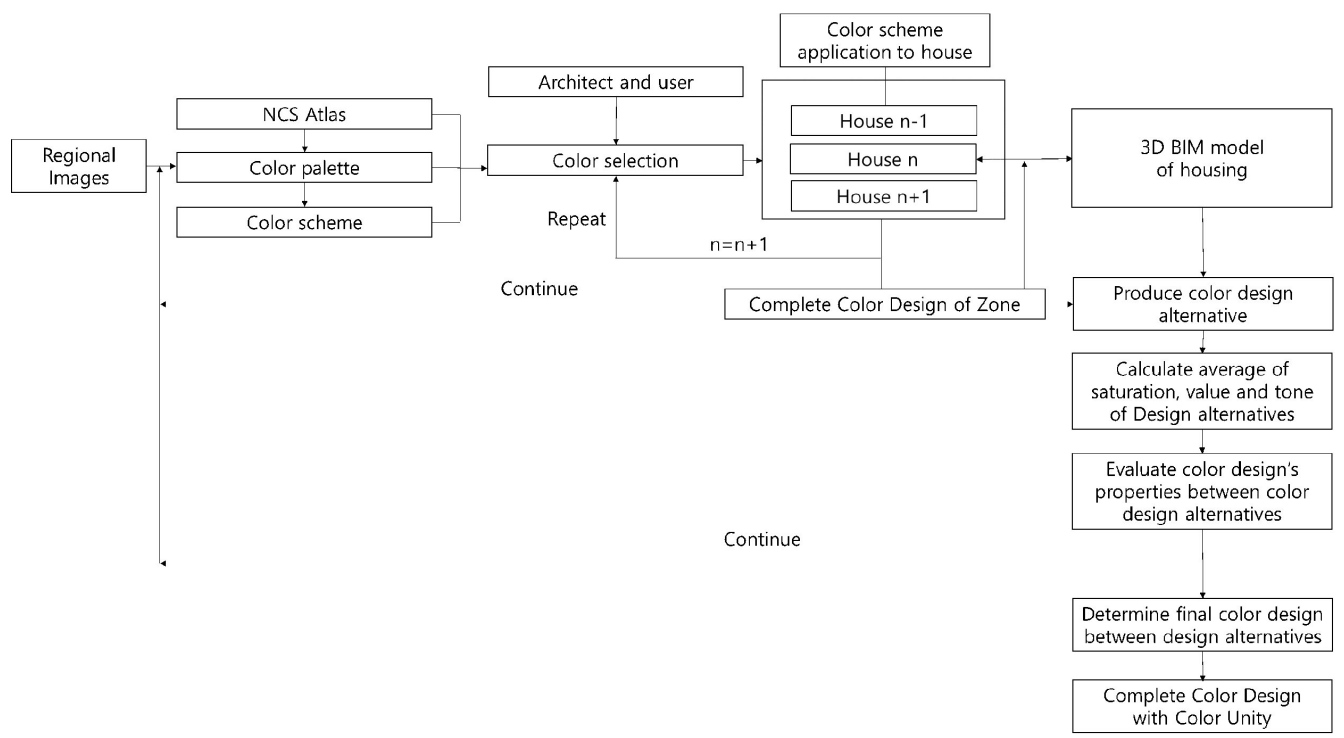

chromaticness $(C)$ within each hue, in this case R90B. The chromaticness specifies how strong the colour is. Colours of the same hue can have a different blackness, chromaticness or whiteness values, which is different nuances. The scales for blackness, whiteness and chromaticness are divided into 100 steps, which as well as in the colour circle can be perceived as percentages. In the triangle is the nuance $1050 \mathrm{se}$ lected[2]. For example, S 1050-R90B, the notation of NCS, represents a Blakness of 10 and a Chromaticness of 50 . The R90B symbolizes $10 \%$ red resemblance and $90 \%$ blue resemblance.

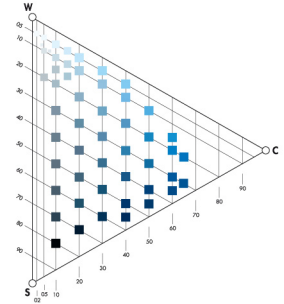

At this stage, one of the color schemes representing emotion is selected and color scheme is applied to the individual house. Figure 3 shows the color scheme(Manav 2017) derived by combining palette colors in conjunction with emotion. Color schemes were developed according to emotion. This study describes color schemes that can be applied to individ- 
ual houses. How to apply the color scheme to individual house is a research issue to be covered in this paper. For example, a color scheme may be applied to a house as random, and it may be automatically applied by a computer as a way to unify the entire image of the village. Of course, the color scheme may be determined manually. When designing a village, choosing appropriate color scheme or color from the color palette is one of the most difficult challenges. Figure 4 is a color palette of the colors contained in the color schemes(McLachlan 2013). The colors in the color palette are represented by color models such as RGB, NCS, and Musell in order to improve the usability of colors. To create a color palette containing such information, it is necessary to convert RGB to Munsell code, RGB to NCS code. In this paper, we use a website $[3,4]$ that provides conversion services.
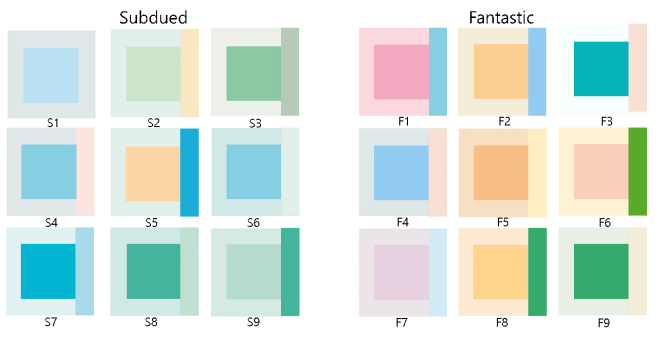

Step 2. COLOR APPLICATION

The second stage is the color zoning stage. A village can consist of several houses, but it can be made up of many houses. If the size of a village is large, applying color zoning to a village in order to realize color diversity and territoriality of the village can be an appropriate design strategy. This is because the landscape image of the village is greatly influenced by the color zoning. However, how to automate color zoning is not the focus of the research. Therefore, this study leaves the problem of color zoning to the architect. It is assumed that the architect applies the color zoning of the village to the BIM model interactively. The next task of color zoning is to apply color codes to individual houses by color zoning.

In this study, Autodesk Revit was used as a mod- eling tool for BIM modeling. The Table 1 shows Identity Data of the BIM Model(Karolina and Krzysztof 2018, Tonn and Bringmann 2018). The target village is a small island village located in Korea and modeled on a total of 90 households. Each house is consisted of a roof, a wall, and a window, and these three kinds of objects are subjected to color application. Houses consisting of three architectural elements are separated by House ID, and can be divided into zones for color scheme by grouping houses.

\begin{tabular}{c|c}
\hline \multicolumn{2}{l}{ Identity Data } \\
\hline Blackness & 5 \\
\hline Chromatic & 40 \\
\hline Color & B10G \\
\hline NCS Code & $0540-\mathrm{B} 10 \mathrm{G}$ \\
\hline Color Scheme & F 1 \\
\hline M Angle & 8.04 \\
\hline M Value & 7.47 \\
\hline M Hue & B \\
\hline House ID & 1 \\
\hline
\end{tabular}

Color attributes(Figure 5) of the NCS and Munsell have also added information to be handled in the color schemes. For the efficient input of these attributes, rule-based filters to visualize the color of the model is used. When NCS color code and color scheme are input according to the color scheme, the RGB values corresponding to the identity data prameter are output and visualized in the BIM model.

\section{Step 3. COLOR ANALYSIS and EVALUATION}

The color analysis step involves analyzing the characteristics of colors for design solutions (eg, Figures $6,7,8)$ generated through color assignment to the house. In this case, the color characteristic means hue, blackness, chroma, etc. in the case of NCS. In the case of Munsell, it means hue, value, and saturation. Design alternative 1 is a design created by a user applying an color scheme intuitively, and design alternative 2 is a design obtained by applying color of a color palette. Design alternative 3 is a design produced by unifying the colors of the roof based on the color scheme. Since the design alternatives are built on the BIM model, it is possible to automatically ex-
Table 1

An Example of Identity Data of BIM Model

Figure 3

Color Schemes with Emotional Words 
Figure 4

Color palette according to the color schemes

Figure 5

Color Attributes of the House

Figure 6 Color Design Alternative 1

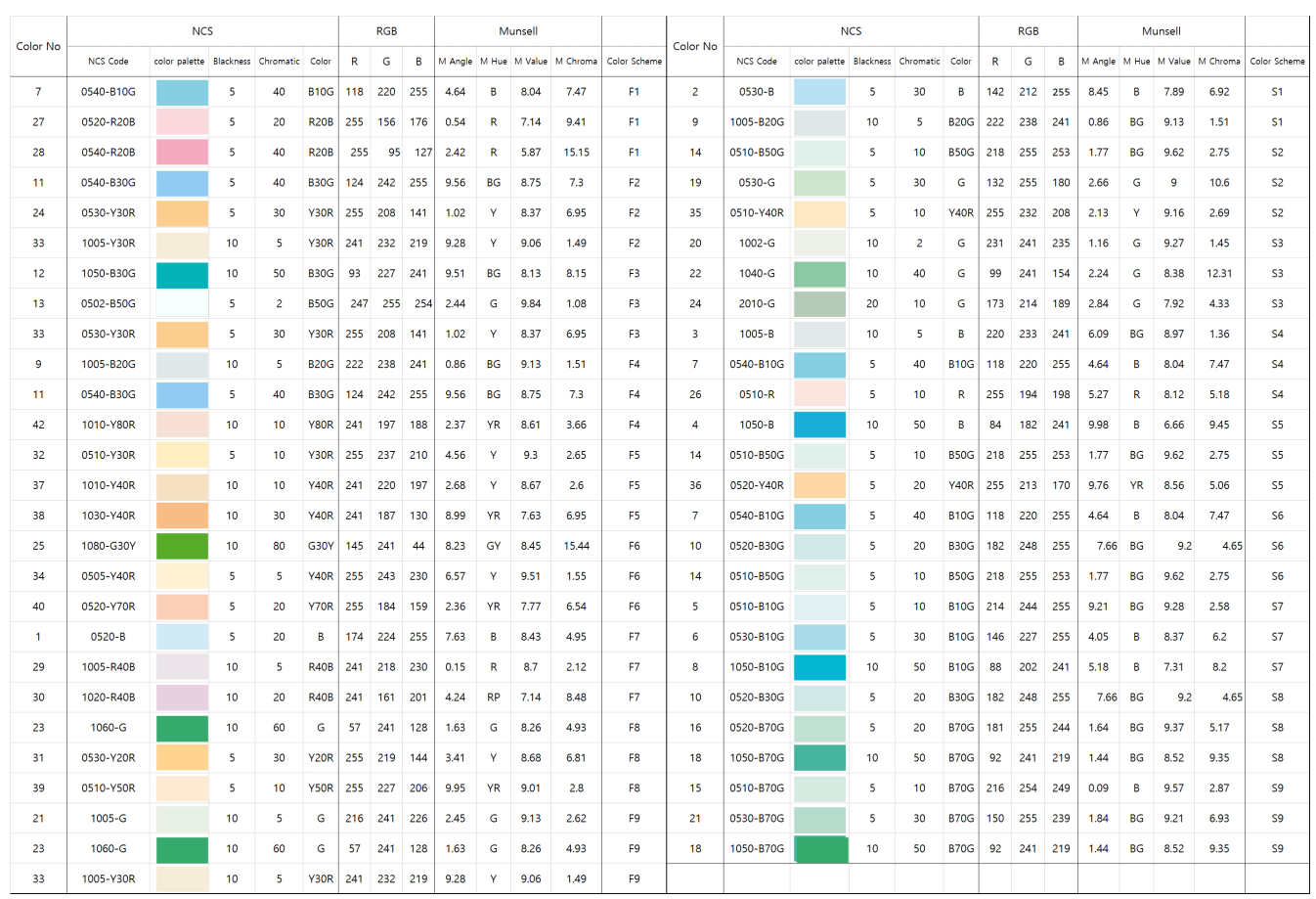

tract color attributes for all the houses in the village. As already shown in Figure 5, the information contained in the BIM model includes house number, architectural elements, color scheme, blackness, chromatic, hue of NCS, color angle, hue, value and saturation of the Munsell. This information provides an opportunity to analyze and evaluate color designs from various perspectives. For example, the average of value and saturation for an individual house can be obtained, also the average value and saturation for the entire village can be calculated. Of course, the value and saturation of color of the architectural element can be obtained. In addition, the distribution of colors used automatically can be calculated.
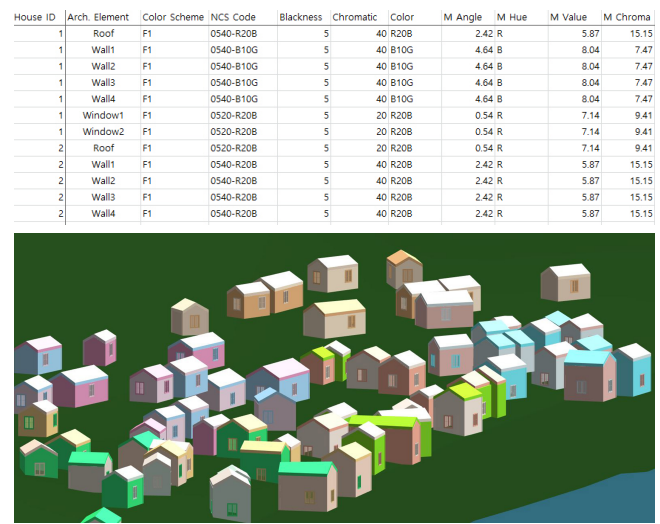

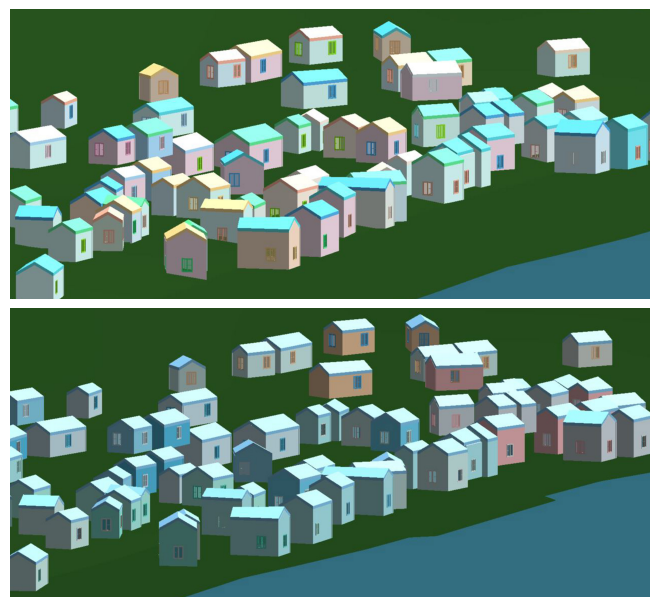

Table 2 shows the average color information for NCS and Munsell. As you can see in the table, there is little difference between the design schemes. However, the color distribution(Figure 9) shows a difference. This result is a simple average of the blackness(value) and chromatic(saturation) of all the colors used in the village. What is the significance of such a simple and implicit result? Is not there a way to improve the proposed color design because of the simplicity and the implication of these results? The answer to this question is that a simple and implicit result has a great implication in providing a reference point for controlling color attributes such as blackness and chromatic. In other words, because the average value of the color attributes can be calculated, lowering or raising the average value tells what color should be selected in subsequent design work. In the design of environmental color, blackness or chromatic value has a deep relationship with color harmony. Therefore, it is important to have information on the direction of color attributes in terms of color harmony. In the traditional color design process, it was almost impossible to know the color attribute value for the ongoing design, but it became possible to grasp this information in the intermediate process of the design in the BIM-based color design. In the conventional color design process, it is almost impossible to know the color attribute value of the ongoing design. However, in the color design process based on the BIM, it is possible to grasp such information in the intermediate process of the color design. Providing specific information on the evolution of the design is a great benefit of the BIM-based color design process.

However, the average value of the color attributes provides the direction of adjustment to the color choice, but does not provide specific information for the color harmony. One way to easily achieve color harmony is to create a color consistency. For example, unifying the blcakness and chromatic of colors or unifying hues increases the consistency of colors. Of course, unifying the color scheme used in color design also has to do with increasing color consistency. For example, to increase the color consistency, the deviation of the color attributes between colors should be minimized as much as possible. Limiting the number of color schemes used in color design can increase the color consistency. The higher the degree of color consistency, the stronger the identity of the architectural village. The color harmony integration-driven design process of this paper is a color consistency centered color design.

\begin{tabular}{lllll}
\cline { 2 - 5 } & NCS & & \multicolumn{2}{c}{ Munsell } \\
& Blackness & Chromatic & Value & Chroma \\
\hline Design Alternative 1 & 7.66 & 25.11 & 8.50 & 5.27 \\
Design Alternative 2 & 7.30 & 22.21 & 8.59 & 6.17 \\
Design Alternative 3 & 6.34 & 22.54 & 8.69 & 5.33 \\
\hline
\end{tabular}

\section{- DISCUSSION}

In this paper, thanks to the color design model based on the BIM model, a method of extracting color attributes has been developed. In addition, a method for analyzing the frequency of color and color schemes has been described. As a result, quantitative evaluation of color design can be made from time to time in the ongoing design process. In addition, the interactive color design became possible and the possibility of freely modifying the design was opened. Accordingly, the basis for improving the quality of color design has been established.

By applying color design methods, the color har-
Figure 7

Color Design

Alternative 2

Figure 8

Color Design

Alternative 3

Table 2

Average Color

Attributes of Design

Alternative 
Figure 9

Frequency of NCS

Colors Applied in

Design Alternative

Design Alt_1

80

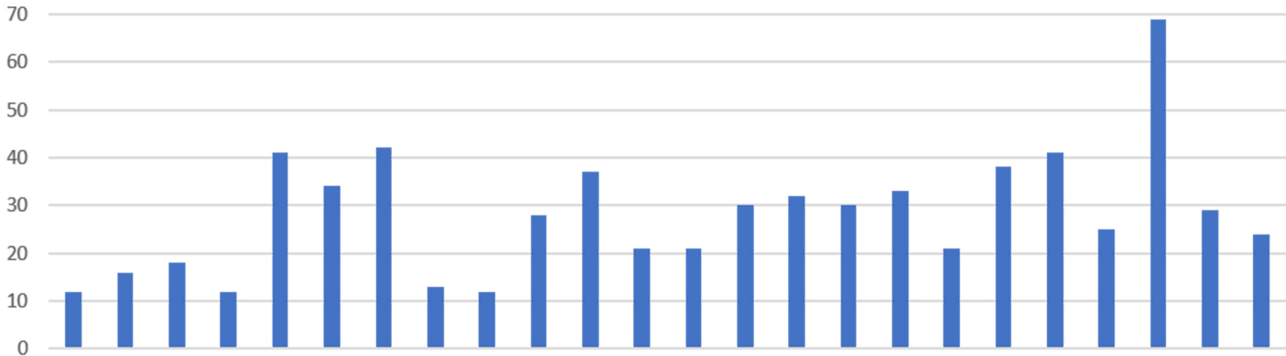

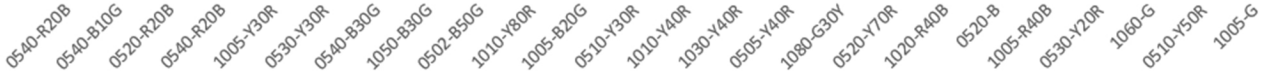

Design Alt_2

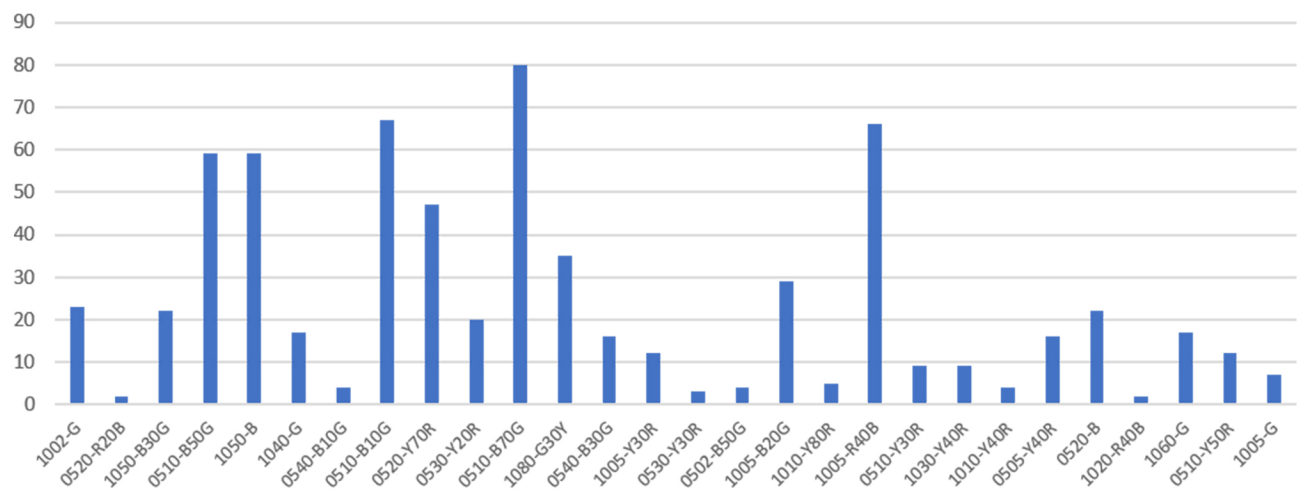

Design Alt_3
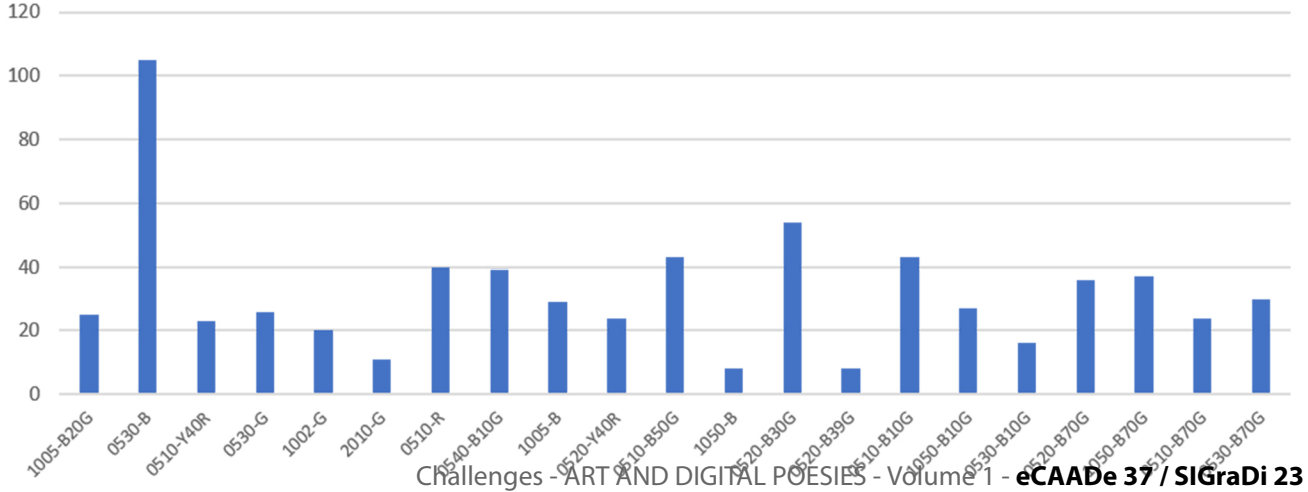
mony can be achieved by increasing the degree of color integration, and ultimately, the aesthetic characteristics of the village can be achieved. This paper describes the analysis result of the design alternative and provides the basis for the architect to facilitate the final decision on the design alternatives. The contribution of this paper is to quantify the attributes of color design intuitively determined in traditional color design. Ultimately, this approach enables color design aiming at color harmony integration in the colorscape of the village. The final conclusion of this study is that the color scheme-based color design process enhance the quality of color design and the BIM-based color model provides an opportunity to quantitatively analyze color design solutions.

\section{ACKNOWLEDGEMENT}

This work was supported by the BK21 Plus funded by the Ministry of Education of Korea.

\section{REFERENCES}

Birren, F 1969, Priciples of Color, Schifferbk

Boeri, C 2017, 'Color Loci Placemaking: The Urban Color Between Needs of Continuity and Rnewal', Color Research and Application, 42, pp. 641-649

Gou, A and Wang, J 2008, 'Research on the Location Characters of Urban Color Plan in China', Color Research and Application, 33, pp. 68-76

Hard, A and Sivik, L 2001, 'A Theory of Colors in Combination-A Descriptive Model Related to the NCS Color-Order System', Color research and application, 26, pp. 4-28

Hu, G, Pan, Z, Zhang, M, Chen, D, Yang, W and Chen, J 2014, 'An Interactive Method for Generating Harmonious Color Schemes', Color Research and Application, 39, pp. 70-78

Ju, $\mathrm{H}$ and Lee, H 2018 'Computational Color Design Process Towards Aesthetic community revitalization', Proceedings of eCAADe 2018, Lodz, pp. 677-686

Karolina, O.W and Krzysztof, N 2018 'Generative BIM Automation Strategies for Prefabricated Multi-Family Housing Design', Proceedings of eCAADe 2018, Lodz, pp. 1-10

Kopacz, J 2003, Color in Three-Dimensional Design, McGraw-Hill
Lancaster, M 1996, Colourscape, Academy Editions

Linton, H 1999, Color in Architecture: Design Methods for Buildings, Interiors, and Urban Spaces, McGraw-Hill

Manav, B 2017, 'Color-emotion associations, designing color schemes for urban environment-architectural settings', Color research and application, 42, pp. 631640

McLachlan, F 2013, Architectural colour in the professional palette, Routledge

Pile, J 1997, Color in Interior Design, McGraw-Hill

Smith, D 2003, 'Environmental Colouration and/or the Design Process', Color research and application, 28, pp. 360-365

Tonn, C, Schmidt, H and Bringmann, O 2018 'Generative BIM Automation Strategies for Prefabricated MultiFamily Housing Design', Proceedings of eCAADe 2018, Lodz, pp. 247-256

Ural, SE and Yilmazer, S 2010, 'The Architectural Color Design Process: An Evaluation of Sequential Media via Semantic Ratings', Color Research and Application, 35, pp. 343-351

Ünver, R and Dokuzer Öztürk, L 2002, 'An example of facade colour design of mass housing', Color research and application, 27, pp. 291-299

[1] www.palettefx.com

[2] https://ncscolour.com/about-us/how-the-ncs-syste m-works/

[3] https://www.idecolor.com/academy/conversor-de-c olor-ncs/

[4] http://wallkillcolor.com/Munsell19/index.htm 